Original Research Article

\title{
Drug utilization pattern in ICU in a tertiary health care institution
}

\author{
Karishma Adhikari*, Swopna Phukan
}

Department of Pharmacology, Gauhati Medical College and Hospital, Guwahati, Assam, India

Received: 08 May 2018

Revised: 15 May 2018

Accepted: 30 May 2018

\section{*Correspondence to:}

Dr. Karishma Adhikari,

Email: karismaadhikari@ gmail.com

Copyright: (C) the author(s), publisher and licensee Medip Academy. This is an openaccess article distributed under the terms of the Creative Commons Attribution NonCommercial License, which permits unrestricted noncommercial use, distribution, and reproduction in any medium, provided the original work is properly cited.

\begin{abstract}
Background: The objective of the study was to evaluate the current prescription pattern of drug utilization so as to find out drug use indicators such as utilization of drugs per prescription that can reflect possibilities of drug interaction and patient compliance and to suggest measures for rational prescriptions in patients admitted in Intensive Care Unit for various medical and surgical indications.

Methods: It was a retrospective, observational hospital based study which was done for 1 year after obtaining permission from the Institutional Human Ethics Committee. The prescriptions of both genders and of any age groups suffering from any medical or surgical indication who were admitted in Intensive Care Unit were included. The parameters assessed were demographic profile of the patient, most common diagnosis, number of days of ICU stay, ICU outcome, number of drugs/prescription, most common group and route of drugs.

Results: Data collected from 560 prescriptions were analyzed using appropriate statistical method and 66\% patients were male. Most common age group was 4160(40\%). Cerebrovascular accident $(22.9 \%)$ was the most common diagnosis followed by septicaemia (20.7\%). Average no. of days of ICU stay was 6.22 days/patient. ICU mortality rate was $58.6 \%$ which was the most common outcome. At an average 15.8 drugs were prescribed per patient. Antibiotics and proton pump inhibitors were the most commonly prescribed drugs in $100 \%$ prescriptions, ceftriaxone $(37.1 \%)$ being the most common antibiotic. Most common route of drug administration was intravenous route $(65 \%)$.

Conclusions: Prescribing guideline is required to reduce the prevalent polypharmacy and to promote appropriate use of antimicrobials based on the culture and sensitivity report.
\end{abstract}

Keywords: Drug utilization, Intensive care unit, Rational prescriptions

\section{INTRODUCTION}

Measurement of drug use in health facilities not only describes drug use patterns and the behaviour of prescribers but also helps in the identification of polypharmacy and the problems associated with it. ${ }^{1}$ Along with that rational drug prescribing which is defined as the use of the least number of drugs to obtain the best possible effect in the shortest period and at a reasonable cost is also an important aspect to be taken into account. ${ }^{2}$

In the absence of a clear, comprehensive and rational drug policy, the production of pharmaceutical preparations in
India is grossly distorted. Thus, Indian markets are flooded with over 70,000 formulations, compared to roughly 350 preparations listed on the WHO Essential Drugs List. ${ }^{3}$ Irrational prescriptions of drugs is of common occurrence in clinical practice. ${ }^{4}$ Important reasons being lack of knowledge about drugs, unethical drug promotions and irrational prescribing habits of clinicians. Irrational prescriptions of drugs can lead to unproductive and risky treatment and possess a major risk of present day medical practice.

Monitoring of prescriptions and drug utilization studies can identify the problems and provide feedback to 
prescribers so as to create an awareness about irrational use of drugs. ${ }^{5}$ So Drug Utilization Research which is defined by WHO in 1977 as "the marketing, distribution, prescription, and use of drugs in a society, with special emphasis on the resulting medical, social and economic consequences" is an essential part of pharmacoepidemiology which can provide insights into both the aspects of drug use and rational drug prescribing like pattern of use, quality of use, determinants of use and outcomes of use. ${ }^{6,7}$

In order to compare drug utilization among different countries and even among health institutions within a country, the utilization has to be expressed in internationally accepted units. The Defined Daily Dose (DDD) is a statistical measure of drug consumption which was developed to overcome objections against traditional units of measurement of drug consumption.

It is defined by the World Health Organization (WHO) as the assumed average maintenance dose per day for a drug used for its main indication..$^{8,9}$

Drug utilization figures should ideally be presented as DDD/100 bed-days which provide a rough estimate of drug consumption in hospital inpatients. ${ }^{8,9}$ and was calculated in this study using the following equation: ${ }^{10}$

DDD/100 bed-days $=$ Drug consumption in the study period $(\mathrm{mg}) \times 100$ DDD (mg) $x$ period of study $x$ bed strength $x$ average occupancy

Intensive Care Unit (ICU) patients are a heterogeneous group, who often suffer from severe illness, multiple organs dysfunction and coexisting medical disorders. Since most of the patients in the ICUs are critically ill and often suffer from multiple complications, polypharmacy becomes unavoidable. ${ }^{10}$ It will lead to increase in incidence of poor treatment response and adverse reactions. ICU services use higher economic resources due to frequent use of high priced drugs and antimicrobial agents. Due to availability of limited funds in developing countries, drugs should be prescribed rationally so that the available funds can be utilized optimally. ${ }^{11}$

Hence this study is to be undertaken to find out the drug utilization pattern and use this information to predict the various drug use indicators and suggest some measures for rational prescriptions in patients admitted in Intensive Care Unit for various medical and surgical indications.

\section{METHODS}

The study was carried out in the Intensive Care Unit (General ICU) of Gauhati Medical College and Hospital, Guwahati for a period of 12 months ( $1^{\text {st }}$ June 2015-31 $1^{\text {st }}$ May 2016) after getting the permission from the Institutional Human Ethics Committee vide letter no.MC/02/2015/208, dated 05-12-2015 and Head of the department, Intensive Care Unit, Gauhati Medical College and Hospital, Guwahati.
This was a retrospective, observational hospital-based study. We have not performed any activity on the patients but only data have been collected. The present study included patients of any age group and both the sexes (male/female) who were admitted in Intensive Care Unit (General ICU) for various medical and surgical conditions. Patient suffering from any medical or surgical indication who were not admitted in Intensive Care Unit (General ICU) were excluded from the study.

A total of 560 prescriptions were collected, analysed and classified during the study period. The prescriptions were collected daily, right from the day of admission till the time of discharge of the patient and following parameters were observed. Confidentiality of the data obtained from the patient case sheets was maintained throughout the study. The data obtained from the analysis of 560 prescriptions was further condensed was subjected to statistical analysis. The overall information generated was presented in the result section.

\section{RESULTS}

In this study more than $66 \%$ patients were male in this ICU which was higher than study by Biswal et al. ${ }^{12}$ The probable reasons may be the sociological factors in this part of the country. In the Indian scenario it is noticed that female populations are reluctant to utilize health care faculties even if they are critically ill (Figure 1).

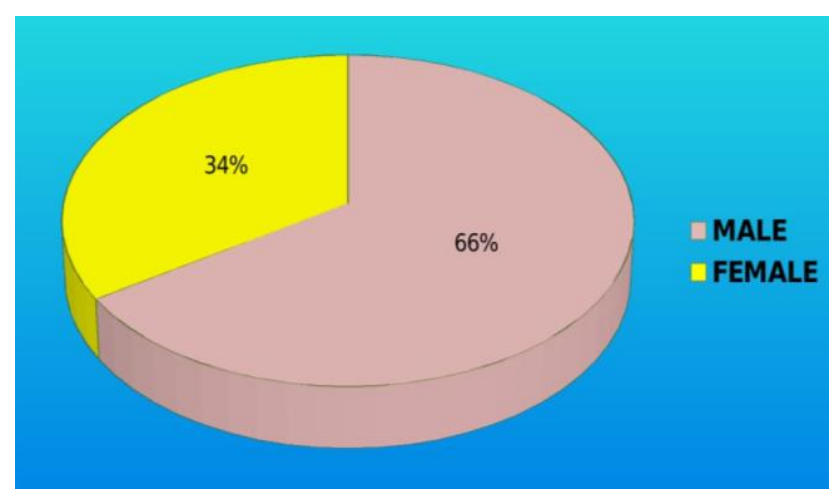

Figure 1: Gender wise distribution of the patients $(n=560)$.

Majority of the patients $(40 \%)$ in both male and female gender belongs to the age group 41-60 years in this study which was lower to study by Prakash et al, where more than $60 \%$ patients were in the same group (Table 1). ${ }^{13}$

Majority of the patients admitted in ICU were suffered from cerebrovascular accident $(22.9 \%)$ in this study which was marginally followed by septicemia $(20.07 \%)$ due to various causes which was in contrast to previous studies of Shankar et al, and Poudel et al, which had reported cancer, cardiovascular emergencies and chronic obstructive pulmonary disease as the major cause of admission (Table 2). $6,14,17$ 
Table 1: Age distribution of the patients $(n=560)$.

\begin{tabular}{|lllll|}
\hline $\begin{array}{l}\text { Age } \\
\text { group } \\
\text { (In } \\
\text { years) }\end{array}$ & $\begin{array}{l}\text { No. of patients } \\
\text { (gender wise } \\
\text { distribution) }\end{array}$ & $\begin{array}{l}\text { Total } \\
\text { no. of } \\
\text { patients }\end{array}$ & $\begin{array}{l}\text { Percentage } \\
\text { of patients } \\
(\%)\end{array}$ \\
\hline & Male & Female \\
\hline$<20$ & 0 & 12 & 12 & 2.1 \\
\hline $21-40$ & 116 & 36 & 152 & 27.1 \\
\hline $41-60$ & 144 & 80 & $\mathbf{2 2 4}$ & $\mathbf{4 0 . 0}$ \\
\hline $61-80$ & 104 & 52 & 156 & 27.9 \\
\hline$>80$ & 4 & 12 & 16 & 2.9 \\
\hline
\end{tabular}

Table 2: Most common diagnosis in general ICU $(n=560)$.

\begin{tabular}{|ll|}
\hline Indication in general ICU & $\%$ Of patients \\
\hline CVA & $22.90 \%$ \\
\hline Septicemia & $20.70 \%$ \\
\hline Surgical & $7.90 \%$ \\
\hline Head injury & $7.10 \%$ \\
\hline Carcinoma & $6.40 \%$ \\
\hline Gynaecological & $5 \%$ \\
\hline Lung infection & $4.30 \%$ \\
\hline Copd/cardiogenic shock & $12.10 \%$ \\
\hline Brain infection & $3.60 \%$ \\
\hline Others & $10.00 \%$ \\
\hline
\end{tabular}

It has also been observed in this study that while CVA, septicemia, head injuries were more common in males; Carcinoma, cardiogenic shock was more common in females. In contrast to our study, one study done in Bhopal found that in all disease condition male patients' outnumbered female patients. ${ }^{15}$

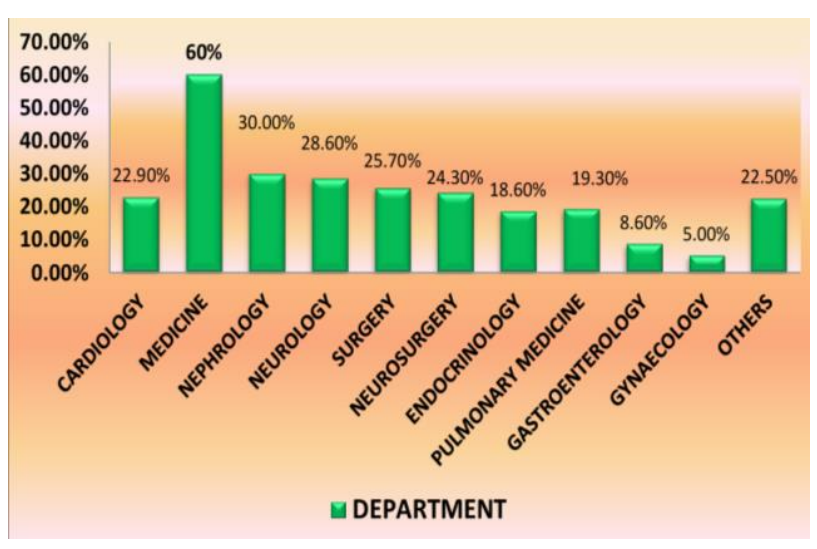

Figure 2: Distribution of the patients in different specialities.

Total $53.5 \%$ patients were having more than one illness in this study, which was slightly less than another published report of Patel et al, who reported it as 57.18 and Shankar et al, (Table 3). ${ }^{16,17}$ Involvement of multiple system leading to complications can be a major reason behind intervention by multiple departments and hence prescription of different medications, thus leading to untoward actions of polypharmacy. Maximum no. of cases was intervened by medicine department in this study accounting around $60 \%$ patients followed by nephrology, neurology, cardiology and almost every department (Figure 2). Hence determination of department wise distribution of the patients is essential to have rough view over the prescription pattern.

\section{Table 3: System wise distribution of the} patients $(\mathbf{n = 5 6 0})$.

\begin{tabular}{|lll|}
\hline $\begin{array}{l}\text { System wise } \\
\text { involvement }\end{array}$ & $\begin{array}{l}\text { Total no. of } \\
\text { patients }\end{array}$ & $\begin{array}{l}\text { Percentage of } \\
\text { patients }\end{array}$ \\
\hline 1 System & 260 & $46.5 \%$ \\
\hline 2 Systems & 144 & $25.7 \%$ \\
\hline 3 Systems & 88 & $15.7 \%$ \\
\hline$>$ 4 Systems & 68 & $12.1 \%$ \\
\hline
\end{tabular}

There is a need for optimizing an efficient distribution and use of ICU resources. For that purpose, there are many measures to assess ICU resource utilization like ICU LOS and the duration of mechanical ventilation, as this is one of the most common procedures in the ICU. Prolonged ICU stay can adversely affect the health status by increasing the risk of infection, complications, and possibly, mortality. It was found in this study that average length of ICU stay was $6.22 \pm 5.09$ days which was more than Shankar et al, but less than Prakash et al. ${ }^{13,17}$ In a study from the United States, the mean LOS of the patients was $5.2 \pm 9.8$ days. Our mean LOS was more than that reported in the American study but since the illness pattern, treatment protocols and economic conditions may be different, comparison can be difficult. Around 49.3\% patients were on mechanical ventilation with an average no. of days as $3.17 \pm 2.76$ days. Hence a large proportion of patients in ICU were on ventilator support and this may be one of the reasons for higher average length of stay in this study (Table 4).

\section{Table 4: Parameters regarding ICU stay in general ICU.}

\begin{tabular}{|ll|}
\hline Parameters & Results $(\mathbf{n}=\mathbf{5 6 0})$ \\
\hline $\begin{array}{l}\text { Average no. of days on mechanical } \\
\text { ventilation }\end{array}$ & $\begin{array}{l}3.17 \pm 2.76 \\
\text { days** }\end{array}$ \\
\hline Average length of stay (LOS) & $6.22 \pm 5.09$ days** \\
\hline ICU mortality rate $(\%)$ & $58.6 \%(328)$ \\
\hline
\end{tabular}

Table 5: Outcome of patients in general ICU $(n=560)$.

\begin{tabular}{|ll|}
\hline Outcome of the patients & $\begin{array}{l}\text { Patients IN } \\
\text { general ICU }\end{array}$ \\
\hline Died & $58.60 \%$ \\
\hline Discharge against medical advice & $21.40 \%$ \\
\hline Leave against medical advice & $9.30 \%$ \\
\hline Improved & $7.10 \%$ \\
\hline Discharge on request & $2.90 \%$ \\
\hline Referred to higher centre & $0.70 \%$ \\
\hline
\end{tabular}


The overall reported ICU mortality in this study was $58.6 \%$ which was higher than previously published reports of $33 \%$ in Smythe et al, and $15.1 \%$ in Shankar et al. (Table 5). ${ }^{17,18}$ This is due to the fact that most of the patient died of septicemia which is again because of antimicrobial resistance leading to antimicrobial failure (Figure 3).

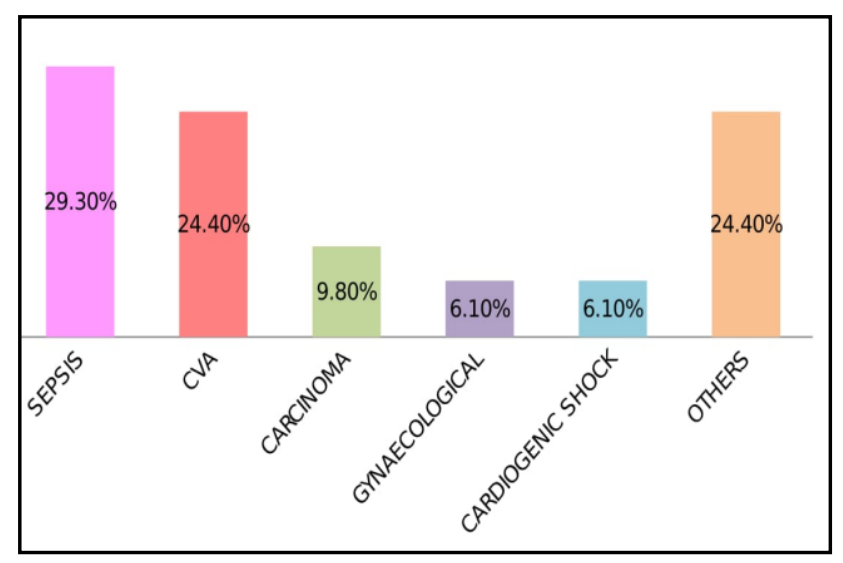

Figure 3: Common indication for ICU mortality.

The average number of drugs per prescription is an important index of a prescription audit. It is recommended that the number of drugs per prescription should be kept as low as possible to minimize the risk of drug interactions, development of bacterial resistance, and hospital costs. ${ }^{17}$ Poly pharmacy is defined as concomitant use of five or more drugs and it could enhance drug interaction. In this study, 560 patients were enrolled who received 8848 drugs and 1748 antibiotics during their stay in the ICU. The average number of drugs prescribed per patient was $15.8 \pm 5.6$, antibiotics constituted $19.80 \%$ of the total drug prescribed. However, the average number of drugs prescribed per patient was higher than Shankar et al. ${ }^{6,17}$ and Smythe et al. ${ }^{18}$ This can be due to multiple co-morbid condition leading to higher length of stay in ICU and consequently multiple medications (Table 6).

Table 6: Basic data regarding drug usage in ICU.

\begin{tabular}{|ll|}
\hline Basic data & General ICU \\
\hline Total no. of drugs & 8848 \\
\hline $\begin{array}{l}\text { Total no. of patients taking the } \\
\text { drugs in ICU }\end{array}$ & 560 \\
\hline $\begin{array}{l}\text { Average no. of drugs per } \\
\text { prescription }\end{array}$ & $\begin{array}{l}15.8 \pm 5.6 \\
\text { drugs/prescription }\end{array}$ \\
\hline Total no. of category of drugs & 205 \\
\hline Total no. of antibiotics & 1748 \\
\hline No. of drugs with generic name & 4032 \\
\hline No. of drugs with brand name & 4816 \\
\hline No. of Fixed Dose Combination & 1384 \\
\hline $\begin{array}{l}\text { Maximum no. of drugs in a } \\
\text { single prescription }\end{array}$ & 35 \\
\hline $\begin{array}{l}\text { Minimum no. of drugs in a single } \\
\text { prescription }\end{array}$ & 06 \\
\hline
\end{tabular}

In spite of various benefits like low cost of drug therapy, increased patient adherence and equivalent therapeutic benefits as brand name alternatives, generic prescribing is not a common practice in India. ${ }^{19-21}$ In this study, around $54.4 \%$ drugs were prescribed by brand names, mainly includes pantoprazole, metronidazole, salbutamolipratropium and furosemide which is higher than Patel et al, around $15.6 \%$ drugs were prescribed as FDC and $62.6 \%$ of drugs prescribed were from the National List of Essential Medicines (Table 7). ${ }^{16,19,20,22}$

Table 7: Fixed dose combinations in ICU.

\begin{tabular}{|ll|}
\hline Fixed dose combinations & $\begin{array}{l}\text { No. prescribed } \\
(\mathbf{n = 1 3 8 4})\end{array}$ \\
\hline Salbutamol+Ipratropium & 328 \\
\hline Multivitamin (oral and with IVF) & 308 \\
\hline Piperacillin-Tazobactum & 200 \\
\hline Imipenum-Cilastin & 76 \\
\hline Ceftriaxone-salbactum & 60 \\
\hline Pentazocin-promethazine & 36 \\
\hline Atorvastatin-aspirin & 36 \\
\hline Others & 340 \\
\hline
\end{tabular}

Drug use indicators are important parameters given by WHO to determine the extent of rationality followed while prescribing medications (Table 8).

\section{Table 8: Drug use indicators (prescribing} indicators) by WHO.

\begin{tabular}{|ll|}
\hline Prescribing indicators & General ICU \\
\hline $\begin{array}{l}\text { Average no. of drugs per } \\
\text { prescription }\end{array}$ & $15.8 \pm 5.6$ drugs \\
\hline $\begin{array}{l}\text { Percentage of prescriptions with an } \\
\text { antibiotic prescribed }\end{array}$ & $100 \%$ \\
\hline $\begin{array}{l}\text { Percentage of drugs prescribed by } \\
\text { generic name }\end{array}$ & $45.6 \%$ \\
\hline $\begin{array}{l}\text { Percentage of prescriptions with an } \\
\text { injection prescribed }\end{array}$ & $98.6 \%$ \\
\hline $\begin{array}{l}\text { Percentage of drugs prescribed } \\
\text { from essential drug list }\end{array}$ & $62.6 \%$ \\
\hline
\end{tabular}

Approximately $65 \%$ of drugs were prescribed as an injectable in $98.6 \%$ of prescriptions, mostly antibiotics, pantoprazole, inotropes, mannitol infusion, furosemide etc. However, use of parenteral drugs $(65 \%)$ is higher than Shankar et al, (52.8\%) but lower than Patel et al, $(86.57 \%) .^{6,16,17}$ The high percentage of injectables was quite explainable since this was an inpatient study with patients mostly having acute and serious illnesses. Injectable drugs are associated with problems of administration and medication errors (Table 9). ${ }^{23}$

Antimicrobial drugs (19.8\%), antipeptic ulcer drugs (6\%) and inotropes $(5.2 \%)$ were the commonly utilized groups similar to John et al. ${ }^{24}$ However, cardiovascular drugs were the commonly used therapeutic class in Biswal et al, and Smythe et al (Table 10). ${ }^{12,18}$ 
Table 9: Formulations of drugs used in ICU.

\begin{tabular}{|ll|}
\hline Formulation of drugs & $\begin{array}{l}\text { \% Of drugs in ICU } \\
(\mathbf{n = 8 8 4 8} \text { drugs })\end{array}$ \\
\hline Oral & $2080(23.5 \%)$ \\
\hline Sublingual & $28(0.32 \%)$ \\
\hline Intravenous & $5752(65 \%)$ \\
\hline Subcutaneous & $136(1.5 \%)$ \\
\hline Intramuscular & $144(1.6 \%)$ \\
\hline Rectal & $88(0.9 \%)$ \\
\hline Topical & $104(1.2 \%)$ \\
\hline Inhalational & $516(5.8 \%)$ \\
\hline
\end{tabular}

Table 10: Most common category of drugs prescribed in ICU.

\begin{tabular}{|ll|}
\hline $\begin{array}{l}\text { Category of drugs } \\
\text { prescribed in ICU }\end{array}$ & $\begin{array}{l}\text { \% Of category of } \\
\text { drugs prescribed in } \\
\text { ICU (n=8848 drugs) }\end{array}$ \\
\hline Antimicrobials & $19.80 \%$ \\
\hline Antiulcer drugs & $6 \%$ \\
\hline Laxative & $3.30 \%$ \\
\hline Antiepileptic drugs & $3.60 \%$ \\
\hline Analgesics & $3.20 \%$ \\
\hline Inotropes & $5.20 \%$ \\
\hline Antihypertensive & $2.70 \%$ \\
\hline Bronchodilator & $5.30 \%$ \\
\hline Diuretics & $5.60 \%$ \\
\hline Vitamin minerals & $4.60 \%$ \\
\hline Hormones & $2 \%$ \\
\hline $\begin{array}{l}\text { Others (Antiemetics, steroids, } \\
\text { probiotics, glycosides, } \\
\text { hypnotics, anticoagulants etc) }\end{array}$ & $38.7 \%$ \\
\hline
\end{tabular}

Ceftriaxone $(37.1 \%)$ and metronidazole $(36.4 \%)$ were the most commonly prescribed antimicrobials similar to John et al, but different from Shankar et al, where penicillin and quinolones were frequently used. ${ }^{17,24}$ The selection of initial appropriate antibiotic combination regimen is important for reducing the high mortality due to septicemia (Table 11). ${ }^{25}$

Aggressive use of antipeptic ulcer drugs was to prevent stress induced ulcer. Atropine was used in patients for bradycardia in late stages of septic shock. Adrenaline was mainly used for cardiac resuscitation. Dopamine, dobutamine and noradrenaline were used in combination with intravenous fluids for the patients of septic and cardiogenic shock. Inotropes are mainly effective in early stages of shock. ${ }^{26}$ The selection of individual inotropes is mainly empirical.

It was observed in this study that DDD/100 bed days was found to be highest for pantoprazole as it was the commonest individual drug found in this study. Among antibiotics metronidazole (34.9\%) have the highest DDD/100 bed days as it was the $2^{\text {nd }}$ most common antibiotic but with most frequent daily dosing. Patel et al, reported that DDD/100 bed days of ceftrixone was 7.41 which was lower compared to our study (Table 12). ${ }^{16}$

\section{Table 11: Most common individual drug prescribed in ICU.}

\begin{tabular}{|ll|}
\hline Common individual drugs & $\begin{array}{l}\text { No. of patients } \\
(\mathbf{n = 5 6 0 )}\end{array}$ \\
\hline Pantoprazole & 504 \\
\hline Salbutamol+Ipratropium & 328 \\
\hline Lactulose & 288 \\
\hline Furosemide & 280 \\
\hline Noradrenaline & 240 \\
\hline Ceftriaxone & 208 \\
\hline Mannitol & 208 \\
\hline Metronidazole & 204 \\
\hline Meropenem & 200 \\
\hline Pipercilin-tazobactum & 180 \\
\hline Atropine & 164 \\
\hline
\end{tabular}

Table 12: DDD/100 BED days of the most commonly used drugs.

\begin{tabular}{|lllll|}
\hline Drugs & A TC code & $\begin{array}{l}\text { Units } \\
\text { prescribed }\end{array}$ & $\begin{array}{l}\text { DDD } \\
\text { (WHO) }\end{array}$ & $\begin{array}{l}\text { DDD/ } \\
\mathbf{1 0 0} \\
\text { BED } \\
\text { days }\end{array}$ \\
\hline Pantoprazole & A02BC02 & 3024 & $40 \mathrm{mg}$ & 86.3 \\
\hline Furosemide & C03C A01 & 2800 & $40 \mathrm{mg}$ & 79.9 \\
\hline Noradrenaline & C01CA03 & 2400 & $6 \mathrm{mg}$ & 11.41 \\
\hline Atropine & A03BA01 & 164 & $1.5 \mathrm{mg}$ & 3.12 \\
\hline Dopamine & C01CA04 & 100 & $0.5 \mathrm{gm}$ & 1.14 \\
\hline Ceftriaxone & J01DD04 & 832 & $2 \mathrm{gm}$ & 11.87 \\
\hline Linezolide & J01XX08 & 1872 & $2 \mathrm{gm}$ & 13.36 \\
\hline Metronidazole & J01X D01 & 3060 & $1.5 \mathrm{gm}$ & 34.9 \\
\hline Meropenem & J01DH02 & 1200 & $2 \mathrm{gm}$ & 17.12 \\
\hline
\end{tabular}

\section{DISCUSSION}

As we all know the intensive care unit (ICU) is a setting where multiple medications are prescribed to critically ill patients which will lead to increase in incidence of poor treatment response and adverse reactions. ${ }^{10,11}$ Here comes the role of the pharmacologist in conducting different studies in different clinical set ups to find out the irrational drug prescription and to give the feedback to the clinicians so as to modify the prescribing pattern and adopt rational means of prescription. Hence studies conducted in different countries have acknowledged irrational drug use in the Intensive Care Units and recommended interventions to improve the drug use pattern. As most of the patients visit this centre, results from this area may reflect the prescribing pattern of whole state.

Certain limitations of our study where authors looked at drug use patterns over a 12-month period only. The study was retrospective and data on the scales used to grade the severity of illness of admitted patients like APACHE were not available in the case record. So authors were unable to 
correlate the drug prescribing patterns with the severity of patient illness.

Certain good prescribing practices have been observed in this study. For example, only $15.6 \%$ drugs were used as FDCs which decreases the chances of use of irrational FDC. Prescription of single drug formulations instead of FDCs may make better prescribing sense in terms of cost and safety. Generic prescribing and use of essential medicines are important parameters to evaluate the rational use of medicines (RUM). It was observed in this study around $45.6 \%$ drugs were prescribed by their generic names which mainly includes antibiotics, mannitol, lactulose and inotropes. Our study fares similar or better than other studies, in this regard. This is attributed to the fact that most drugs supplied by hospital pharmacy are generic products, which are likely to be chosen by prescribers. This practice suggests there were fewer gaps in communication between the hospital pharmacists and the prescribers regarding the list of available drugs. Essential drugs offer a cost-effective solution to many health problems in a developing country. Knowledge, availability and access to drugs in the NLEM promote rational therapeutics. Almost 5522 drugs (62.6\%) were prescribed from NLEM which mainly includes antibiotics like levofloxacin, vancomycin, ceftriaxone; insulin, furosemide, mannitol, steroids like dexamethasone, inotropes like adrenaline etc. ${ }^{16,19,20,22}$

But except few good prescribing habits there were lots of loopholes and irrational practices in this study. Length of stay of ICU was $6.22 \pm 5.09$ days which was quite higher than other studies which increases the complications and cost burden for the patients. ${ }^{13,17}$ Also, the ICU mortality was around $58.6 \%$ which indicate multiple complications prevailing in this set up. ${ }^{17,18}$ Another major reason can be low reporting of antibiotic culture and sensitivity which results into antibiotic failure and hence septicemia turned out to be the major cause of ICU mortality which was quite high as compared to other studies. Around 15.8 \pm 5.6 drugs/prescription were prescribed which indicates high degree of polypharmacy exist in this set up resulting in therapeutic failure, drug-drug interaction, adverse drug reaction and increase cost burden for the patients. ${ }^{6,17,18}$ Also these cost burden issue was quite obvious by the fact that around $30 \%$ patients didn't complete their treatment but were discharged/absconded against medical advice. Lastly low data available in case sheets regarding reporting of antibiotic culture and sensitivity not only leads to increase in antibiotic resistance but also push the patient towards the negative consequences of injudicious use of antibiotics such as increase antibiotic failure and mortality.

\section{CONCLUSION}

So, to conclude with keeping in considerations the aims and objectives of this study, on evaluation of prescription pattern to find out drug utilization, we found that antimicrobials were the most frequently prescribed group of drugs whereas pantoprazole was the most frequently prescribed individual drug. Among antimicrobials ceftriaxone followed by metronidazole were the most commonly prescribed drugs.

Regarding the utilization of drugs per prescription (drug use indicator) it was found that multiple antimicrobials were prescribed per prescription mainly as intravenous preparations along with many other groups of drugs and hence there was high rate of polypharmacy ( $>15$ drugs) prevailing in all prescriptions to treat multiple complications

So various measures for rational prescription can be use of broad spectrum antimicrobials instead of multiple antimicrobials per prescription, use of antibiotic culture and sensitivity in every case, avoiding polypharmacy by implementation of local antibiotic management programs, infectious disease specialist consultation, restricted authorization to prescribe antibiotics and preparation of antibiotic use policy for better patient compliance by reducing cost burden, therapeutic failure, adverse drug reactions, drug-drug interactions.

Hence to promote rational prescribing it is essential to conduct drug utilization studies and to use the data as feedback for educating and training the physicians as well as undergraduate students adequately regarding the need for rational prescribing.

\section{ACKNOWLEDGEMENTS}

At the very outset, authors offer their prayers to the Almighty and our parents whose blessings will guide them on the path of wisdom and success. Authors take this opportunity to express their deep sense of respect and gratitude towards Dr. A.K. Adhikari, Principal-cum-Chief Superintendent, Gauhati Medical College and Hospital, and Dr B.K Bezbaruah, Registrar, SSUHS for guiding them throughout, with his valuable suggestions. Authors also like to thank the faculty of Department of Pharmacology and Intensive care unit for their support.

\section{Funding: No funding sources \\ Conflict of interest: None declared}

Ethical approval: The study was approved by the Human Ethical Committee (MC/02/2015/208)

\section{REFERENCES}

1. WHO. Action programme for Essential Drugs. How to investigate drug use in health facilities. Published by WHO. $1993 . \quad$ Available at: apps.who.int/medicinedocs/pdf/.../s2289e.pdf

2. Vijayakumar TM, Sathyavati D, Subhashini T, Grandhi S, Dhanaraju MD. Assessment of Prescribing Trends and Rationality of Drug Prescribing. Int $\mathbf{J}$ of Pharmacol. 2011;7:140-3.

3. Patel V, Vaidya R, Naik D, Borker P. Irrational drug use in India: A prescription survey from Goa. J Postgrad Med. 2005;51:9-12. 
4. Ramsay LE. Bridging the gap between clinical pharmacology and rational drug prescribing. Br J clin pharmacol. 1993;35:575-6. [PMC free article] [PubMed]

5. Pradhan SC, Shewade DG, Shashindren CH, Bapna JS. Drug utilization studies. National Med J India. 1988;1(4):185-9. Available at: archive.nmji.in/approval/archive/...1/.../original-andreview-articles-3.pdf

6. Shankar PR, Upadhyay DK, Subish P, Bhandari RB, Das B. Drug utilisation among older inpatients in a teaching hospital in Western Nepal. Singapore Med J. 2010;51:28-34. [PubMed]

7. World Health Organization (WHO). Introduction to drug utilization research. Geneva: World Health Organization; 2003.

8. Truter I, Wiseman IC, Kotze TJ. The defined daily dose as a measure of drug consumption in South Africa. A preliminary study. S Afr Med J. 1996;86(6):675-9.

9. Eisen SA, Miller DK, Woodward RS, Spitznagel E, Przybeck TR. The Effect of Prescribed Daily Dose Frequency on Patient Medication Compliance. Arch Intern Med. 1990;150(9):1881-4.

10. Sharma P, Kapoor B. Study of prescribing pattern for rational drug therapy. JK science. 2003;5(3):107-9.

11. Shankar PR, Partha P, Dubey AK, Mishra P, Deshpande VY. Intensive care unit drug utilization in a teaching hospital in Nepal. Kathmandu Univ Med J (KUMJ). 2005;3(10):130-7. [PubMed]

12. Biswal S, Mishra P, Malhotra S, Puri GD, Pandhi P. Drug utilization pattern in the intensive care unit of a tertiary care hospital. J of Clin Pharmacol. 2006 Aug 1;46(8):945-51.

13. Shelat PR, Gandhi AM, Patel PP. A Study of Drug Utilization Pattern According to Daily Define Dose in Intensive Care Unit (ICU) s at Tertiary Care Teaching Hospital, India. J of You Pharmaci. 2015 Oct $1 ; 7(4): 349$.

14. Paudel R, Palaian S, Giri B, Hom KC, Sah AK, Poudel A, et al. Clinical profile and drug utilization pattern in an intensive care unit of a teaching hospital in Western Nepal. Arch Pharm Pract. 2011;2:163-9.

15. Gupta R. Drug prescribing pattern in intensive care unit (ICU) in a Tertiary care teaching hospital in central india. Int J Pharm Bio Sci. 2015;6(3):325-9.

16. Patel MK, Barvaliya MJ, Patel TK, Tripathi CB. Drug utilization pattern in critical care unit in a tertiary care teaching hospital in India. Int $\mathbf{J}$ of Cri Illn and Inju Scienc. 2013 Oct;3(4):250.

17. Shankar PR, Partha P, Dubey AK, Mishra P, Deshpande VY. Intensive care unit drug utilization in a teaching hospital in Nepal. Kathmandu Univ Med J (KUMJ). 2005;3(10):130-7. [PubMed]

18. Smythe MA, Melendy S, Jahns B, Dmuchowski C. An exploratory analysis of medication utilization in a medical intensive care unit. Crit Care Med. 1993;21(9):1319-23. [PubMed]

19. Haas JS, Phillips KA, Gerstenberger EP, Seger AC. Potential savings from substituting generic drugs for brand-name drugs: Medical expenditure panel survey, 1997-2000. Ann Intern Med. 2005;142(11):891-7. [PubMed]

20. Shrank WH, Hoang T, Ettner SL, Glassman PA, Nair $\mathrm{K}$, DeLapp D et al. The implications of choice: prescribing generic or preferred pharmaceuticals improves medication adherence for chronic conditions. Arch Intern Med. 2006;166:332-7. [PubMed]

21. Nightingale SL. From the Food and Drug Administration. Promotional Practices of Pharmacy Benefits Management Companies. JAMA. 1998;279:645. [PubMed]

22. WHO Essential medicine list; 2013. Available at: http://www.who.int/medicines/publications. Accessed 01 Jan 2013.

23. Taxis K, Barber N. Ethnographic study of incidence and severity of intravenous drug errors. BMJ. 2003;326:684. [PMC free article] [PubMed]

24. John LJ, Devi P John P, Guido S. Drug utilization study of antimicrobial agents in medical intensive care unit. Asian J Pharm Clin Res. 2011;4(2):81-4.

25. Díaz-Martín A, Martínez-González ML, Ferrer R, Ortiz-Leyba C, Piacentini E, Lopez- Pueyo MJ, et al. Antibiotic prescription patterns in the empiric therapy of severe sepsis: Combination of antimicrobials with different mechanisms of action reduces mortality. Crit Care. 2012;16(6):R223.

26. Bangash MN, Kong ML, Pearse RM. Use of inotropes and vasopressor agents in critically ill patients. Br J Pharmacol. 2012;165:2015-33. [PubMed]

Cite this article as: Adhikari K, Phukan S. Drug utilization pattern in ICU in a tertiary health care institution. Int J Basic Clin Pharmacol 2018;7:1396402. 